\title{
Spiroaxillarone A, a Symmetric Spirobisnaphthalene with an Original Skeleton from Cyanotis axillaris.
}

\author{
Awat Wisetsai, ${ }^{\dagger}$ Ratsami Lekphrom, ${ }^{\dagger}$ Jaursup Boonmak, ${ }^{\ddagger}$ Sujittra Youngme,${ }^{\ddagger}$ and \\ Florian T. Schevenels*, $\dagger$ \\ †Natural Products Research Unit, Department of Chemistry, and Center for Innovation in Chemistry, \\ Faculty of Science, Khon Kaen University, Khon Kaen 40002, Thailand \\ ¥Materials Chemistry Research Unit, Department of Chemistry and Center of Excellence for \\ Innovation in Chemistry, Faculty of Science, Khon Kaen University, Khon Kaen 40002, Thailand
}

\section{Supporting Information}

\section{Table of contents}

1. Experimental section $\quad$ S2

1.1 General experimental procedures $\quad$ S2

1.2 Biological material $\quad$ S2

1.3 Extraction and isolation $\quad$ S2

1.4 Conformational analysis and ECD calculations of Spiroaxillarone A (1) and its enantiomer S3

1.5 Esterification of 1 to the tetrabromoester $1 \mathrm{a} \quad \mathrm{S} 3$

1.6 X-Ray crystallography of the tetrabromobenzoate derivative 1a

$\begin{array}{ll}1.7 \text { Antimalarial activity assay } & \text { S7 }\end{array}$

$\begin{array}{ll}1.8 \text { References } & \text { S7 }\end{array}$

2. Original spectral data of Spiroaxillarone A (1) S8

2.1 NMR spectra of Spiroaxillarone A (1) S8

2.2 HR-ESIMS spectrum of Spiroaxillarone A (1) S11

2.3 IR spectrum of Spiroaxillarone A (1) S12

2.4 UV spectrum of Spiroaxillarone A (1) in methanol $\quad$ S12

$2.5^{1} \mathrm{H}$ NMR spectrum $(400 \mathrm{MHz})$ of $1 \mathrm{a}$

$2.6{ }^{13} \mathrm{C}$ NMR spectrum $(150 \mathrm{MHz})$ of $1 \mathbf{a}$

2.7 HR-ESIMS spectrum of 1a 


\section{Experimental section}

\subsection{General experimental procedures}

Optical rotations were measured on a JASCODIP-1000 digital polarimeter (JASCO Inc., U.S.A.). CD and UV spectra were recorded on a JASCO J-810 apparatus. IR spectra were obtained using a Bruker Tenser 27 spectrophotometer (Bruker, Germany). NMR spectra were recorded on a Varian Mercury Plus 400 spectrometer (Varian Inc., U.S.A.) or on a Bruker Avance 600 NMR spectrometer (Bruker, Germany) using $\mathrm{CDCl}_{3}$ and $\mathrm{CD}_{3} \mathrm{OD}$ as solvents. The internal standards were referenced from the residual peak of $\mathrm{CD}_{3} \mathrm{OD}$ for 1 and the residual peak of $\mathrm{CDCl}_{3}$ for $1 \mathrm{a}$. The HRESITOFMS were recorded on a Bruker micrOTOF mass spectrometer (Brucker, Germany). Column chromatography was carried out on MERCK silica gel 60 (230-400 mesh) (Merck, Darmstadt, Germany). Thin-layer chromatography was carried out with pre-coated MERCK silica gel 60 PF254 (Merck, Darmstadt, Germany); the spots were visualized under UV light $(254$ and $365 \mathrm{~nm}$ ) and further stained by spraying $p$-anisaldehyde and then heated until charred. Unless otherwise noted, all chemicals were obtained from commercially available sources and were used without further purification.

\subsection{Biological material}

The aerial parts of Cyanotis axillaris (L.) D. Don (voucher $n^{\circ}$ R. LekpromKKU013) were collected locally from Pla Pak District, Nakhon Phanom Province, Thailand, in September 2018. The plant was characterized by Prof. Dr. Pranom Chantaranothai, Faculty of Science, Khon Kaen University.

\subsection{Extraction and isolation}

Air-dried aerial parts of Cyanotis axillaris (L.) D. Don $(1.00 \mathrm{~kg})$ were ground to powder and extracted with EtOAc $(3 \times 3 \mathrm{~L})$. The EtOAc extract was concentrated to give $17.0 \mathrm{~g}$ of crude EtOAc extract (brown-green viscous oil). This crude extract was then subjected to silica gel flash column chromatography (FCC) with hexanes before applying a polarity gradient with EtOAc. Each fraction $(200 \mathrm{~mL})$ was observed by TLC. Fractions with similar TLC patterns were combined, providing seven major fractions $\left(E F_{1}-E F_{7}\right)$. The major fraction $\mathrm{EF}_{4}$ was further purified by silica gel $\mathrm{FCC}$, eluting with a polarity gradient of $\mathrm{MeOH}: \mathrm{CH}_{2} \mathrm{Cl}_{2}$, to give four subfractions, $\mathrm{EF}_{4.1}-\mathrm{EF}_{4.4}$. Subfraction $\mathrm{EF}_{4.4}$ was purified by silica gel flash column chromatography, eluting with $\mathrm{CH}_{2} \mathrm{Cl}_{2}: \mathrm{MeOH}$ (95:5) to give compound 1 (77.0 mg) as a brown amorphous solid.

Spiroaxillarone A (1), Brown amorphous solid; $[\alpha]_{D}^{25}-217^{\circ}$ (c 0.10, MeOH); UV (MeOH) $\lambda_{\max }(\log \varepsilon)$ 265 (5.01), 370 (4.59); $\mathrm{CD}(\mathrm{MeOH}) 218$ ( $\Delta \varepsilon+19.73), 231$ ( $\Delta \varepsilon-14.61), 260(\Delta \varepsilon+45.8), 277(\Delta \varepsilon-54.29)$; IR (neat) $v_{\max } 3300,2962,2936,1635,1559,1449,1367,1291,1203,1144,1107,1055$ and $876 \mathrm{~cm}^{-}$ 1; ${ }^{1} \mathrm{H}$ NMR and ${ }^{13} \mathrm{C}$ NMR data, see Table 1 and Table S1; HRESIMS m/z $359.0502(\mathrm{M}+\mathrm{Na})^{+}(\mathrm{Calcd}$ $\mathrm{m} / \mathrm{z} 359.0526)$.

Table S1. NMR data for Spiroaxillarone $A$ (1) in $\mathrm{CDCl}_{3}+\mathrm{CD}_{3} \mathrm{OD}$ (10 drops)

\begin{tabular}{|c|c|c|c|c|}
\hline Position $n^{\circ}$ & $\begin{array}{l}\text { Methanol, } d_{4} \\
\delta_{H}[J(H z)]\end{array}$ & $\delta_{C}$ & COSY & HMBC \\
\hline $1,1^{\prime}$ & & 198.7 & & \\
\hline 2,2 & $5.92, d(9.6)$ & 120.6 & $3,3^{\prime}$ & C-9, 10 \\
\hline $3,3^{\prime}$ & $7.50, \mathrm{~d}(10.0)$ & 149.5 & $2,2^{\prime}$ & $C-1,4,5$ \\
\hline $4,4^{\prime}$ & & 136.3 & & \\
\hline $5,5^{\prime}$ & $6.83, \mathrm{~s}$ & 116.8 & & C-3, 4, 6, 7, \\
\hline $6,6^{\prime}$ & & 144.7 & & \\
\hline $7,7^{\prime}$ & & 148.5 & & \\
\hline $8,8^{\prime}$ & $6.21, \mathrm{~s}$ & 115.9 & & $C-6,7,9,10$ \\
\hline $9,9^{\prime}$ & & 122.0 & & \\
\hline 10 & & 68.8 & & \\
\hline
\end{tabular}




\subsection{Conformational analysis and ECD calculations of Spiroaxillarone A (1) and its enantiomer}

For theoretical ECD spectra, possible configuration of compound 1 was established for both geometry optimizations and electronic excited calculations. Geometrical optimizations of the structure were taken under density functional theory (DFT) calculations. These calculations were performed with hybrid density functional B3LYP, and using $6-311 \mathrm{~g}(\mathrm{~d}, \mathrm{p})$ to diffuse basis set (Figure S1). In the single point energy calculations, the vertical transition energies to the valence excited-states were computed with the time-dependent density functional theory (TD-DFT) method using the long-range corrected functional CAM-B3LYP at the $6-311++g(d, p)$ level $(\sigma=0.30)$. The bulk solvent effects were evaluated using the Conductor-like Polarizable Continuum Model (C-PCM). All calculations were performed with GAUSSIAN 09 program. ${ }^{1}$ The results are shown in Figure 5 and Figure S2. In the 200$500 \mathrm{~nm}$ region, the theoretically calculated ECD pattern for the $10 \mathrm{~S}$ absolute configuration was in agreement with the experimental CD spectrum of 1, although noticeable UV shifts were observed for several peaks (especially at 218,231 and $376 \mathrm{~nm}$ ).

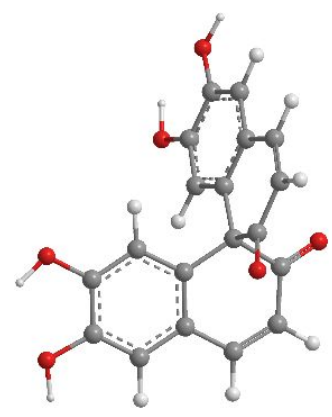

Figure S1. 3D conformation of 1 obtained by optimization at B3LYP/6-311G(d,p)

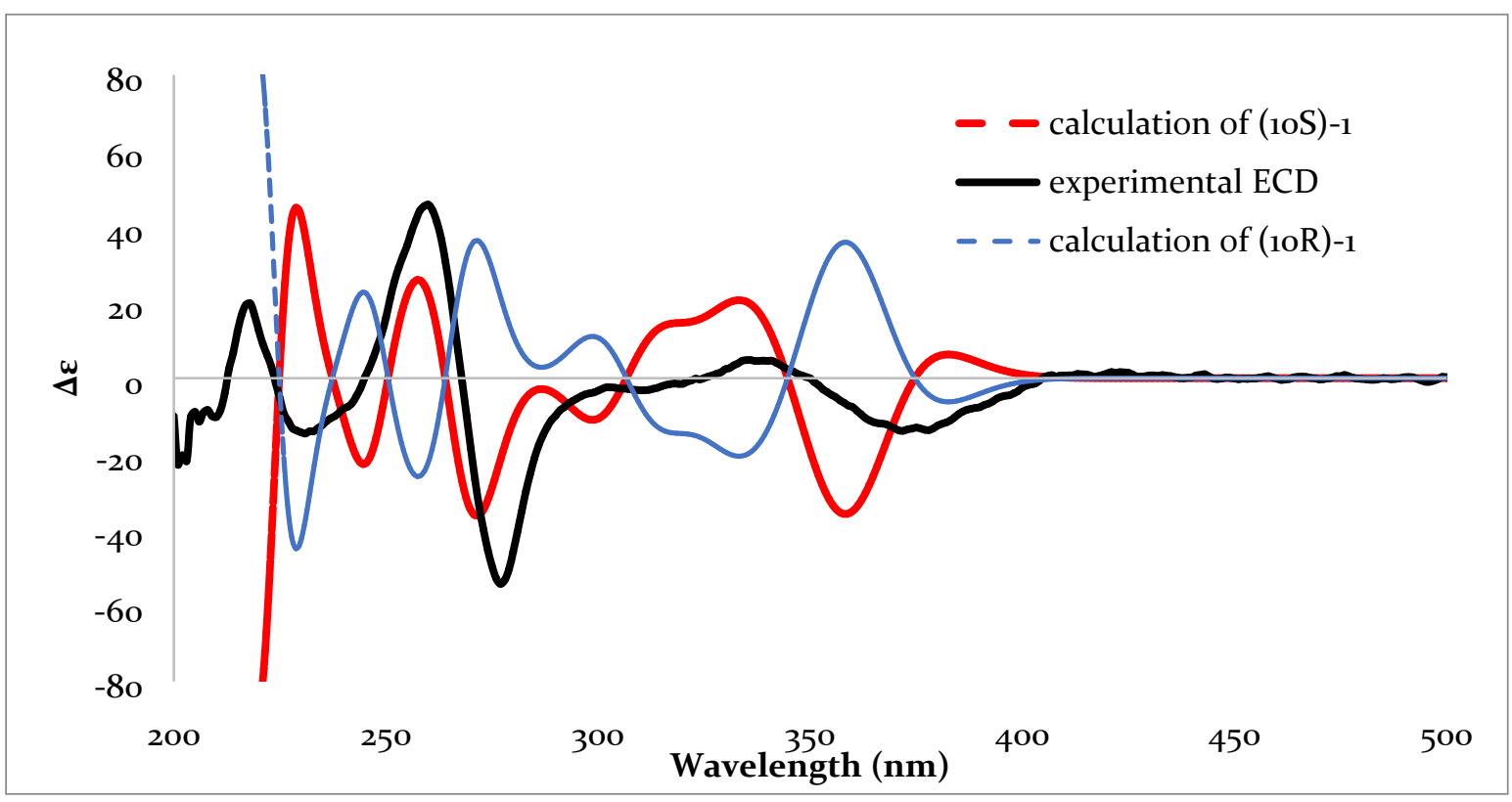

Figure S2. The overlaid experimental CD spectrum of 1 (black line) and calculated ECD spectra of 1 (red line) and its enantiomer (blue line).

\subsection{Esterification of 1 to the tetrabromoester $1 \mathrm{a}$}

To a solution of 1 (20 mg, $0.060 \mathrm{mmol}, 1.0$ eq.) in $\mathrm{CH}_{2} \mathrm{Cl}_{2}(1.2 \mathrm{~mL})$ were added 2,4,6-collidine $(0.16$ $\mathrm{mL}, 1.2 \mathrm{mmol}, 20$ eq.) and 4-bromobenzoyl chloride $(91.4 \mathrm{mg}, 0.4 \mathrm{mmol}, 7.0$ eq.) at room temperature $\left(30-35^{\circ} \mathrm{C}\right)$. The reaction was monitored by TLC. After $14 \mathrm{~h}$, aqueous $\mathrm{NH}_{4} \mathrm{Cl}(2.5 \mathrm{~mL})$ was added. The aqueous layer was extracted with $\mathrm{CH}_{2} \mathrm{Cl}_{2}(3 \times 2.0 \mathrm{~mL})$. The combined organic layers were dried $\left(\mathrm{Na}_{2} \mathrm{SO}_{4}\right)$, filtered and concentrated. Purification over silica gel $\left(\mathrm{CH}_{2} \mathrm{Cl}_{2}\right)$ provided 1a $(5.0 \mathrm{mg}, 4.7$ $\mu \mathrm{mol}, 8 \%$ yield) as a white solid. ${ }^{1} \mathrm{H}$ NMR $\left(400 \mathrm{MHz}, \mathrm{CDCl}_{3}\right): \delta 7.87(\mathrm{~d}, J=9.2 \mathrm{~Hz}, 4 \mathrm{H}), 7.84(\mathrm{~d}, J=$ 
$8.8 \mathrm{~Hz}, 4 \mathrm{H}), 7.62(\mathrm{~d}, J=10.0 \mathrm{~Hz}, 2 \mathrm{H}), 7.55-7.52(\mathrm{~m}, 10 \mathrm{H}), 6.88(\mathrm{~s}, 2 \mathrm{H}), 6.20(\mathrm{~d}, J=10.0 \mathrm{~Hz}, 2 \mathrm{H})$ ppm. ${ }^{13} \mathrm{C}$ NMR $\left(150 \mathrm{MHz}, \mathrm{CDCl}_{3}\right): \delta 192.3,163.3,162.8,145.9,144.0,142.4,139.9,132.3,132.2$, $131.8,131.7,129.7,129.6,129.4,127.4,127.3,124.8,124.6,124.0,70.4$ ppm. HRESIMS m/z $1090.7961(\mathrm{M}+\mathrm{Na})^{+}($Calcd $\mathrm{m} / \mathrm{z}$ 1090.7955)

\subsection{X-Ray crystallography of the tetrabromobenzoate derivative 1a}

The X-ray crystal data for compound 1a was collected on a Bruker D8 Quest PHOTON100 CMOS diffractometer with graphite-monochromated MoKa radiation. The diffraction data were integrated using the SAINT. ${ }^{2}$ The multiscan absorption corrections were done by the SADABS program. ${ }^{3}$ The structure was solved by intrinsic phasing using SHELXT (Apex2 program suite) and refined by fullmatrix least-squares methods using SHELXTL with the ShelXle user interface. ${ }^{4,5,6}$ All non-hydrogen atoms were refined anisotropically while the $\mathrm{H}$-atoms were located on calculated positions. The crystallographic data, bond lengths and angles are listed in Tables S2-S4. The crystallographic data was deposited with CCDC no. 1868309. These data can be obtained free of charge from The Cambridge Crystallographic Data Centre via http://www.ccdc.cam.ac.uk/data_request/cif.

Table S2. Crystal data and structure refinement for 1a

\begin{tabular}{|c|c|}
\hline Formula & $\mathrm{C}_{47} \mathrm{H}_{24} \mathrm{Br}_{4} \mathrm{O}_{10}$ \\
\hline Formula weight & 1068.30 \\
\hline Temperature/K & $298(2)$ \\
\hline Crystal system & monoclinic \\
\hline Space group & $\mathrm{P} 2{ }_{1} / \mathrm{c}$ \\
\hline $\mathrm{a} / \AA \AA$ & $21.7025(13)$ \\
\hline $\mathrm{b} / \AA \AA$ & $25.4319(13)$ \\
\hline$c / \AA ̊$ & $7.4422(4)$ \\
\hline$\alpha /^{\circ}$ & 90 \\
\hline$\beta /^{\circ}$ & $97.660(2)$ \\
\hline$y /{ }^{\circ}$ & 90 \\
\hline Volume $/ \AA^{3}$ & $4071.0(4)$ \\
\hline Z & 4 \\
\hline$\rho_{\text {calc }} \mathrm{g} / \mathrm{cm}^{3}$ & 1.743 \\
\hline$\mu / \mathrm{mm}^{-1}$ & 4.017 \\
\hline$F(000)$ & 2104.0 \\
\hline Radiation & $\operatorname{MoK\alpha }(\lambda=0.71073)$ \\
\hline Reflections collected & 88948 \\
\hline Independent reflections & $7993\left(R_{\text {int }}=0.2330\right)$ \\
\hline Goodness-of-fit on $\mathrm{F}^{2}$ & 1.001 \\
\hline Final $R$ indexes $(I \geq 2 \sigma(I))$ & $\mathrm{R}_{1}=0.0733, \mathrm{wR}_{2}=0.1441$ \\
\hline Final $R$ indexes (all data) & $\mathrm{R}_{1}=0.2048, w \mathrm{R}_{2}=0.1887$ \\
\hline Largest diff. peak/hole / e $\AA^{-3}$ & $0.76 /-0.58$ \\
\hline
\end{tabular}




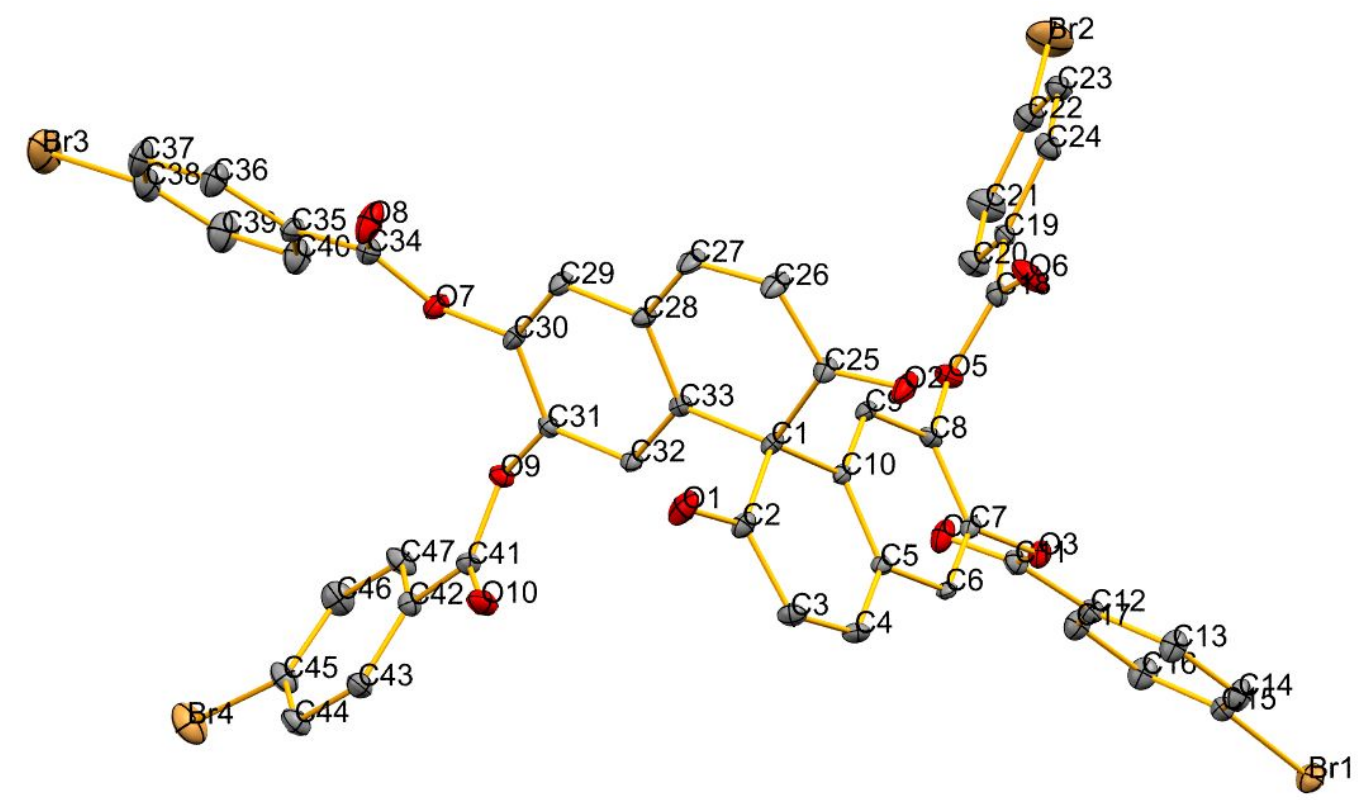

Figure S3. X-ray crystal structure of $1 \mathrm{a}$ with atom labelling scheme. $\mathrm{H}$-atoms are omitted for clarity

Table S3. The bond lengths $(\AA)$ for compound 1a

$\begin{array}{llllll}\text { Br1 } & \text { C15 } & 1.893(7) & \text { C13 } & \text { C14 } & 1.389(10) \\ \text { Br2 } & \text { C22 } & 1.889(8) & \text { C14 } & \text { C15 } & 1.352(10) \\ \text { Br3 } & \text { C38 } & 1.893(9) & \text { C15 } & \text { C16 } & 1.360(10) \\ \text { Br4 } & \text { C45 } & 1.898(8) & \text { C16 } & \text { C17 } & 1.381(10) \\ \text { O1 } & \text { C2 } & 1.212(8) & \text { C18 } & \text { C19 } & 1.465(10) \\ \text { O2 } & \text { C25 } & 1.202(8) & \text { C19 } & \text { C20 } & 1.363(10) \\ \text { O3 } & \text { C11 } & 1.377(8) & \text { C19 } & \text { C24 } & 1.384(9) \\ \text { O3 } & \text { C7 } & 1.397(7) & \text { C20 } & \text { C21 } & 1.389(11) \\ \text { O4 } & \text { C11 } & 1.178(8) & \text { C21 } & \text { C22 } & 1.377(12) \\ \text { O5 } & \text { C18 } & 1.354(8) & \text { C22 } & \text { C23 } & 1.338(11) \\ \text { O5 } & \text { C8 } & 1.393(8) & \text { C23 } & \text { C24 } & 1.370(10) \\ \text { O6 } & \text { C18 } & 1.188(8) & \text { C25 } & \text { C26 } & 1.439(10) \\ \text { O7 } & \text { C34 } & 1.335(9) & \text { C26 } & \text { C27 } & 1.330(10) \\ \text { O7 } & \text { C30 } & 1.418(8) & \text { C27 } & \text { C28 } & 1.438(9) \\ \text { O8 } & \text { C34 } & 1.200(9) & \text { C28 } & \text { C33 } & 1.390(8) \\ \text { O9 } & \text { C41 } & 1.339(8) & \text { C28 } & \text { C29 } & 1.400(9) \\ \text { O9 } & \text { C31 } & 1.396(7) & \text { C29 } & \text { C30 } & 1.374(9) \\ \text { O10 } & \text { C41 } & 1.192(8) & \text { C30 } & \text { C31 } & 1.377(9) \\ \text { C1 } & \text { C33 } & 1.525(9) & \text { C31 } & \text { C32 } & 1.395(9) \\ \text { C1 } & \text { C10 } & 1.530(8) & \text { C32 } & \text { C33 } & 1.387(8) \\ \text { C1 } & \text { C2 } & 1.564(10) & \text { C34 } & \text { C35 } & 1.492(10) \\ \text { C1 } & \text { C25 } & 1.565(9) & \text { C35 } & \text { C40 } & 1.341(11) \\ \text { C2 } & \text { C3 } & 1.436(10) & \text { C35 } & \text { C36 } & 1.383(11) \\ \text { C3 } & \text { C4 } & 1.326(9) & \text { C36 } & \text { C37 } & 1.384(12) \\ \text { C4 } & \text { C5 } & 1.435(9) & \text { C37 } & \text { C38 } & 1.341(13) \\ \text { C5 } & \text { C10 } & 1.393(8) & \text { C38 } & \text { C39 } & 1.348(13) \\ \text { C5 } & \text { C6 } & 1.405(8) & \text { C39 } & \text { C40 } & 1.397(12) \\ \text { C6 } & \text { C7 } & 1.359(9) & \text { C41 } & \text { C42 } & 1.492(10) \\ \text { C7 } & \text { C8 } & 1.375(9) & \text { C42 } & \text { C47 } & 1.355(10) \\ \text { C8 } & \text { C9 } & 1.382(9) & \text { C42 } & \text { C43 } & 1.369(9) \\ \text { C9 } & \text { C10 } & 1.379(9) & \text { C43 } & \text { C44 } & 1.364(10) \\ \text { C11 } & \text { C12 } & 1.478(9) & \text { C44 } & \text { C45 } & 1.362(11) \\ \text { C12 } & \text { C13 } & 1.372(10) & \text { C46 } & \text { C47 } & 1.399(11) \\ \text { C12 } & \text { C17 } & 1.381(9) & & & \end{array}$


Table S4. The bond angles $\left({ }^{\circ}\right)$ for compound 1a

\begin{tabular}{|c|c|c|c|c|c|c|c|}
\hline C11 & O3 & $\mathrm{C} 7$ & $119.8(5)$ & $\mathrm{C} 23$ & $\mathrm{C} 22$ & $\mathrm{C} 21$ & $121.5(8)$ \\
\hline C18 & $\mathrm{O} 5$ & $\mathrm{C} 8$ & $119.2(5)$ & $\mathrm{C} 23$ & $\mathrm{C} 22$ & $\mathrm{Br} 2$ & $118.8(7)$ \\
\hline C34 & $\mathrm{O} 7$ & C30 & $121.1(6)$ & $\mathrm{C} 21$ & $\mathrm{C} 22$ & $\mathrm{Br} 2$ & $119.6(7)$ \\
\hline C41 & 09 & C31 & $118.1(5)$ & C22 & $\mathrm{C} 23$ & C24 & $119.5(8)$ \\
\hline C33 & C1 & C10 & $110.5(5)$ & $\mathrm{C} 23$ & C24 & C19 & $121.0(7)$ \\
\hline C33 & C1 & C2 & $107.0(5)$ & $\mathrm{O} 2$ & $\mathrm{C} 25$ & C26 & $123.0(6)$ \\
\hline C10 & C1 & C2 & $114.3(5)$ & $\mathrm{O} 2$ & $\mathrm{C} 25$ & C1 & $119.3(6)$ \\
\hline C33 & C1 & C25 & 114.1(5) & C26 & $\mathrm{C} 25$ & C1 & $117.7(6)$ \\
\hline C10 & $\mathrm{C} 1$ & C25 & 107.2(5) & $\mathrm{C} 27$ & $\mathrm{C} 26$ & $\mathrm{C} 25$ & $122.4(7)$ \\
\hline C2 & C1 & C25 & $103.6(5)$ & C26 & $\mathrm{C} 27$ & C28 & $123.3(7)$ \\
\hline 01 & $\mathrm{C} 2$ & C3 & $123.6(7)$ & C33 & $\mathrm{C} 28$ & $\mathrm{C} 29$ & $119.7(6)$ \\
\hline 01 & $\mathrm{C} 2$ & C1 & $118.4(6)$ & C33 & $\mathrm{C} 28$ & $\mathrm{C} 27$ & $120.4(6)$ \\
\hline C3 & C2 & C1 & $118.0(6)$ & C29 & C28 & C27 & $120.0(6)$ \\
\hline C4 & C3 & C2 & $122.8(7)$ & C30 & C29 & C28 & $120.0(6)$ \\
\hline C3 & C4 & C5 & $123.4(6)$ & C29 & C30 & C31 & $120.4(6)$ \\
\hline C10 & C5 & C6 & $118.7(6)$ & C29 & C30 & $\mathrm{O} 7$ & $125.0(6)$ \\
\hline C10 & C5 & C4 & $120.5(6)$ & C31 & C30 & $\mathrm{O} 7$ & $114.3(6$ \\
\hline C6 & C5 & C4 & $120.7(6)$ & C30 & C31 & C32 & $120.2(6$ \\
\hline C7 & C6 & C5 & $121.0(6)$ & C30 & C31 & 09 & $117.8(6$ \\
\hline C6 & $\mathrm{C} 7$ & C8 & $119.7(6)$ & C32 & C31 & 09 & $121.8(6$ \\
\hline C6 & C7 & O3 & $118.1(6)$ & C33 & C32 & C31 & $119.7(6)$ \\
\hline C8 & C7 & O3 & $122.1(6)$ & C32 & C33 & C28 & $119.9(6)$ \\
\hline C7 & C8 & C9 & $120.8(6)$ & C32 & C33 & C1 & 119.3 \\
\hline C7 & C8 & O5 & $119.5(6)$ & $\mathrm{C} 28$ & C33 & C1 & 120.8( \\
\hline C9 & C8 & O5 & 119.6(6) & O8 & C34 & O7 & $123.5(7)$ \\
\hline C10 & C9 & C8 & $120.0(6)$ & 08 & C34 & C35 & $125.2(8)$ \\
\hline C9 & C10 & C5 & $119.9(6)$ & $\mathrm{O} 7$ & C34 & C35 & $111.2(7)$ \\
\hline C9 & C10 & C1 & $119.6(5)$ & C40 & C35 & C36 & $120.0(8)$ \\
\hline C5 & C10 & C1 & $120.6(6)$ & $\mathrm{C} 40$ & C35 & C34 & $124.0(8$ \\
\hline O4 & C11 & O3 & $122.9(7)$ & C36 & C35 & $\mathrm{C} 34$ & $116.1(8$ \\
\hline $\mathrm{O} 4$ & C11 & C12 & $125.6(7)$ & C35 & C36 & C37 & $119.3(9$ \\
\hline O3 & C11 & C12 & $111.5(6)$ & C38 & C37 & C36 & $120.0(9)$ \\
\hline C13 & C12 & C17 & $118.7(7)$ & C37 & C38 & C39 & $121.0(9$ \\
\hline C13 & C12 & C11 & $123.5(7)$ & C37 & C38 & $\mathrm{Br} 3$ & $118.1(9$ \\
\hline C17 & C12 & C11 & $117.8(7)$ & C39 & C38 & $\mathrm{Br} 3$ & $120.9(9$ \\
\hline C12 & C13 & C14 & $120.1(7)$ & C38 & C39 & C40 & $119.7(\mathrm{C}$ \\
\hline C15 & C14 & C13 & $120.0(7)$ & C35 & $\mathrm{C} 40$ & C39 & 120.0 \\
\hline C14 & C15 & C16 & 121.2(7) & O10 & C41 & O9 & 123.0( \\
\hline C14 & C15 & $\mathrm{Br} 1$ & $120.4(6)$ & O10 & C41 & C42 & 124.3( \\
\hline C16 & C15 & $\mathrm{Br} 1$ & 118.5(5) & O9 & C41 & C42 & 112.8( \\
\hline C15 & C16 & C17 & $119.0(7)$ & C47 & C42 & C43 & 119.8 \\
\hline C16 & C17 & C12 & $121.0(7)$ & C47 & C42 & C41 & $123.1(7)$ \\
\hline 06 & C18 & O5 & $121.9(7)$ & C43 & C42 & C41 & 117.1(7) \\
\hline O6 & C18 & C19 & $126.0(7)$ & C44 & C43 & C42 & $121.5(7)$ \\
\hline $\mathrm{O} 5$ & C18 & C19 & $112.1(6)$ & C45 & C44 & C43 & $119.0(7$ \\
\hline $\mathrm{C} 20$ & C19 & $\mathrm{C} 24$ & $118.6(7)$ & C44 & C45 & C46 & 120.97 \\
\hline $\mathrm{C} 20$ & C19 & C18 & $123.5(7)$ & C44 & C45 & $\mathrm{Br} 4$ & $118.8(6$ \\
\hline C24 & C19 & C18 & 117.9(7) & C46 & C45 & $\mathrm{Br} 4$ & $120.3(7$ \\
\hline C19 & C20 & C21 & $120.7(7)$ & C45 & C46 & C47 & $118.8(8)$ \\
\hline C22 & C21 & C20 & 118.6(8) & C42 & C47 & C46 & $119.9(7$ \\
\hline
\end{tabular}




\subsection{Antimalarial activity assay}

Antimalarial activity was evaluated against the parasite Plasmodium falciparum (K1, multidrug resistant strain), cultivated in in vitro conditions, ${ }^{7}$ in RPMI 1640 medium containing 20 mM HEPES ( $N$ 2-hydroxyethylpiperazine- $N^{\prime}$-2-ethanesulfonic acid), $32 \mathrm{mM} \mathrm{NaHCO}_{3}$ and $10 \%$ heat activated human serum with $3 \%$ erythrocytes, in a humidified $37{ }^{\circ} \mathrm{C}$ incubator with $3 \% \mathrm{CO}_{2}$. The culture is passaged with fresh mixture of erythrocytes and medium for every day to maintain cell growth. Quantitative assessment of activity in vitro was determined by means of the microculture radioisotope technique. ${ }^{8}$ Briefly, a mixture of $200 \mu \mathrm{l}$ of $1.5 \%$ erythrocytes with $1 \%$ parasitemia at the early ring stage is preexposed to $25 \mu \mathrm{l}$ of the medium containing a test sample dissolved in $1 \%$ DMSO $(0.1 \%$ final concentration) for $24 \mathrm{~h}$. Subsequently, $25 \mu \mathrm{l}$ of $\left[{ }^{3} \mathrm{H}\right]$ hypoxanthine (Amersham, USA) in culture medium $(0.5 \mu \mathrm{Ci})$ is added to each well and the plates are incubated for an additional $24 \mathrm{~h}$. The inhibitory concentration $\left(\mathrm{IC}_{50}\right)$ represents the concentration that causes $50 \%$ reduction in parasite growth as indicated by the in vitro uptake of $\left[{ }^{3} \mathrm{H}\right]$-hypoxanthine by $P$. Falciparum. The standard compound was mefloquine. Compound 1 exhibited cytotoxic activity against $P$. falciparum with an $\mathrm{IC}_{50}$ value of $2.32 \mu \mathrm{M}$. The positive control (mefloquine) had an $\mathrm{IC}_{50}$ value of $55.30 \mathrm{nM}$.

\subsection{References}

1. Frisch, M. J.; Trucks, G. W.; Schlegel, H. B.; Scuseria, G. E.; Robb, M. A.; Cheeseman, J. R.; Scalmani, G.; Barone, V.; Mennucci, B.; Petersson, G. A.; Nakatsuji, H.; Caricato, M.; Li, X.; Hratchian, H. P.; Izmaylov, A. F.; Bloino, J.; Zheng, G.; Sonnenberg, J. L.; Hada, M.; Ehara, M.; Toyota, K.; Fukuda, R.; Hasegawa, J.; Ishida, M.; Nakajima, T.; Honda, Y.; Kitao, O.; Nakai, H.; Vreven, T.; Montgomery, J. A.; Peralta, J. E.; Ogliaro, F.; Bearpark, M.; Heyd, J. J.; Brothers, E.; Kudin, K. N.; Staroverov, V. N.; Kobayashi, R.; Normand, J.; Raghavachari, K.; Rendell, A.; Burant, J. C.; lyengar, S. S.; Tomasi, J.; Cossi, M.; Rega, N.; Millam, J. M.; Klene, M.; Knox, J. E.; Cross, J. B.; Bakken, V.; Adamo, C.; Jaramillo, J.; Gomperts, R.; Stratmann, R. E.; Yazyev, O.; Austin, A. J.; Cammi, R.; Pomelli, C.; Ochterski, J. W.; Martin, R. L.; Morokuma, K.; Zakrzewski, V. G.; Voth, G. A.; Salvador, P.; Dannenberg, J. J.; Dapprich, S.; Daniels, A. D.; Farkas; Foresman, J. B.; Ortiz, J. V.; Cioslowski, J.; Fox, D. J. Gaussian 09, Revision B.01; Gaussian, Inc.: Walling.

2. SAINT 4.0 Software Reference Manual; Siemens Analytical X-Ray Systems Inc.: Madison, WI, 2000.

3. Sheldrick, G. M. SADABS, Program for Empirical Absorption correction of Area Detector Data; University of Göttingen: Göttingen, Germany, 2000.

4. Sheldrick, G. M. SHELXT - integrated space-group and crystal-structure determination. Acta Cryst. 2015, A71, 3-8.

5. Sheldrick, G. M. A short history of SHELX. Acta Cryst. 2008, A64, 112-122.

6. Hübschle, C. B.; Sheldrick, G. M.; Dittrich, B. ShelXle: a Qt graphical user interface for SHELXL. J. Appl. Cryst. 2011, 44, 1281-1284.

7. Trager, W.; Jensen, J. B. Human malaria parasites in continuous culture. Science 1976, 193, 673-675.

8. Desjardin, R. E.; Canfield, C. J.; Haynes, J. D.; Chulay, J. D. Quantitative assessment of antimalarial activity in vitro by a semiautomated microdilution technique. Antimicrob. Agents Chemother. 1979, 16, 710-718. 


\section{Original spectral data of Spiroaxillarone A (1)}

\subsection{NMR spectra of Spiroaxillarone A (1)}

${ }^{1} \mathrm{H}$ NMR spectrum $(400 \mathrm{MHz})$ of Spiroaxillarone $\mathrm{A}(1)$

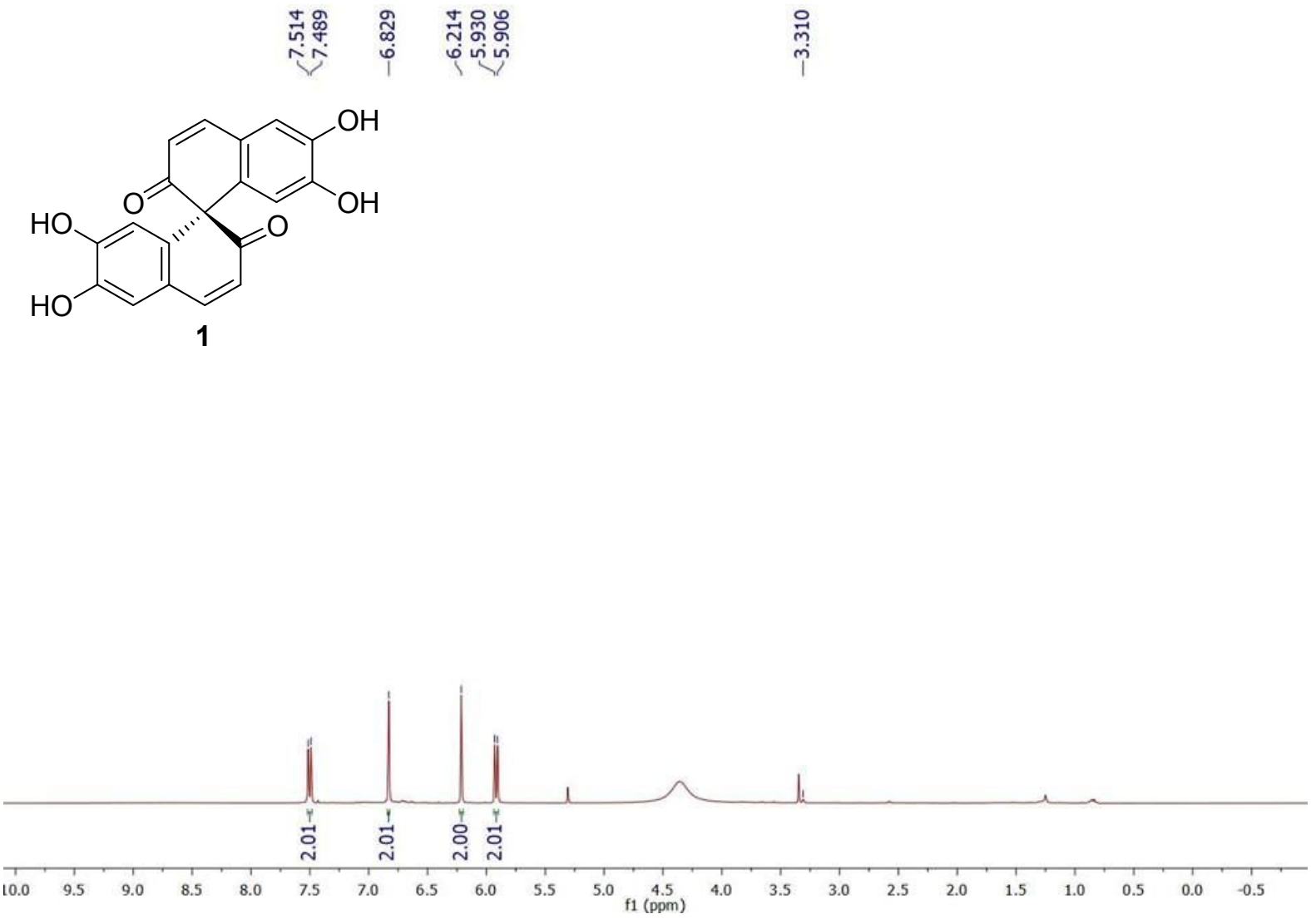

${ }^{13} \mathrm{C}$ NMR spectrum (100 MHz) of Spiroaxillarone A (1)

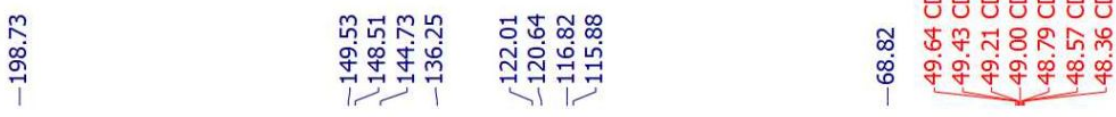<smiles>O=C1C=Cc2cc(O)c(O)cc2C12C(=O)C=Cc1cc(O)c(O)cc12</smiles>

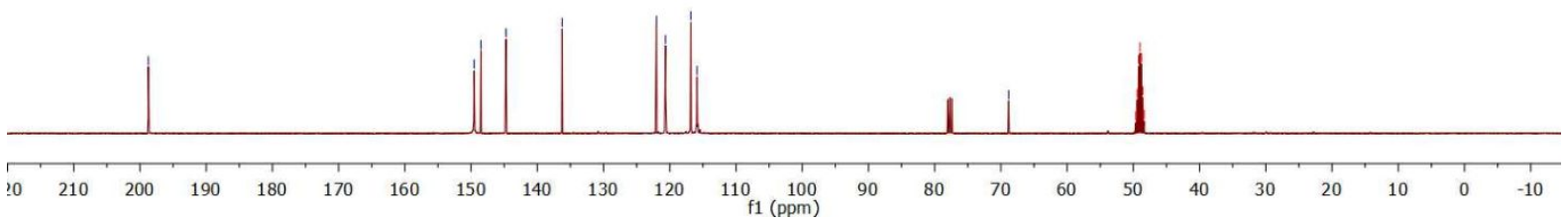


DEPT spectrum of Spiroaxillarone A (1)

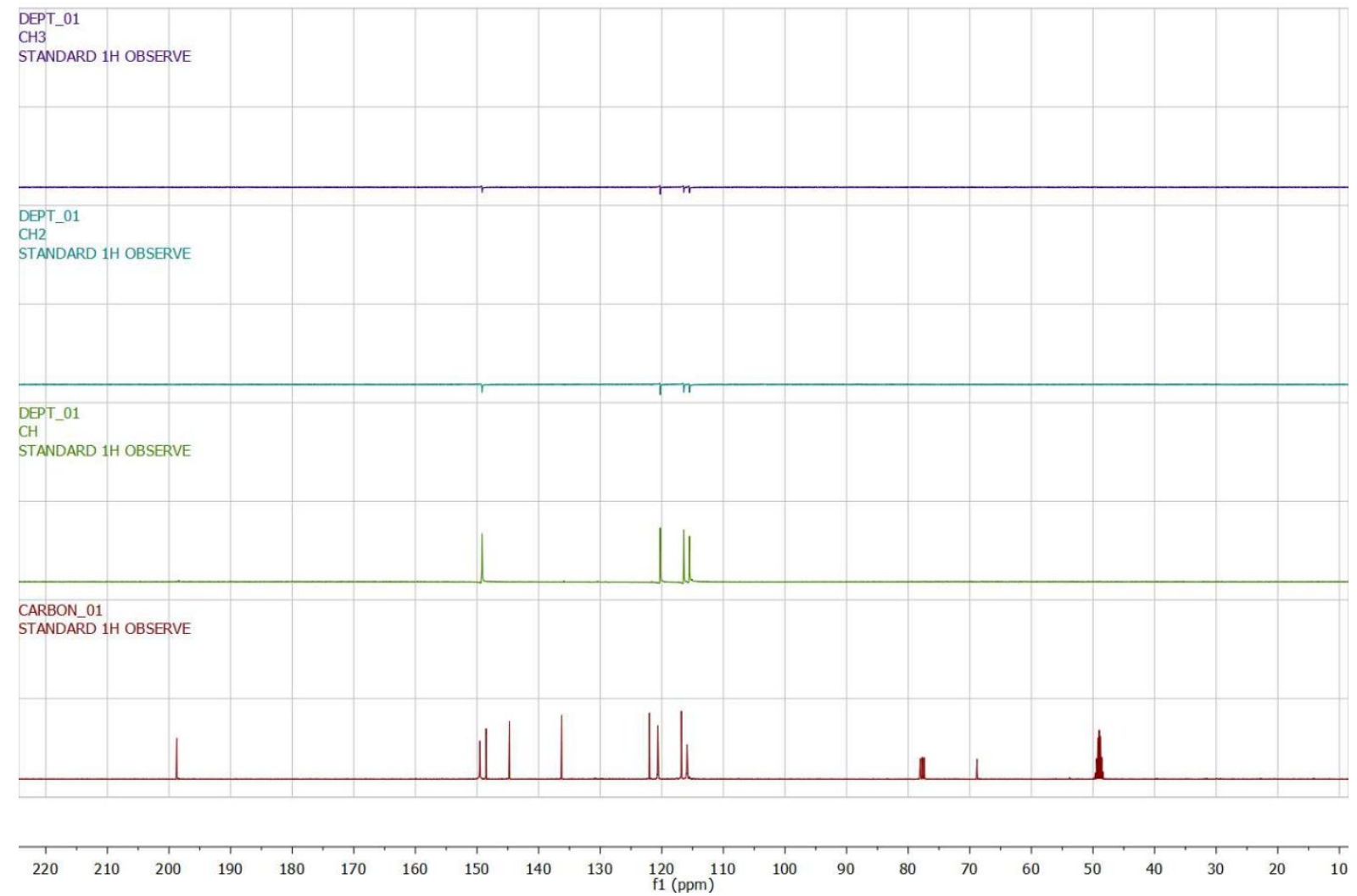

HMQC spectrum of Spiroaxillarone A (1)

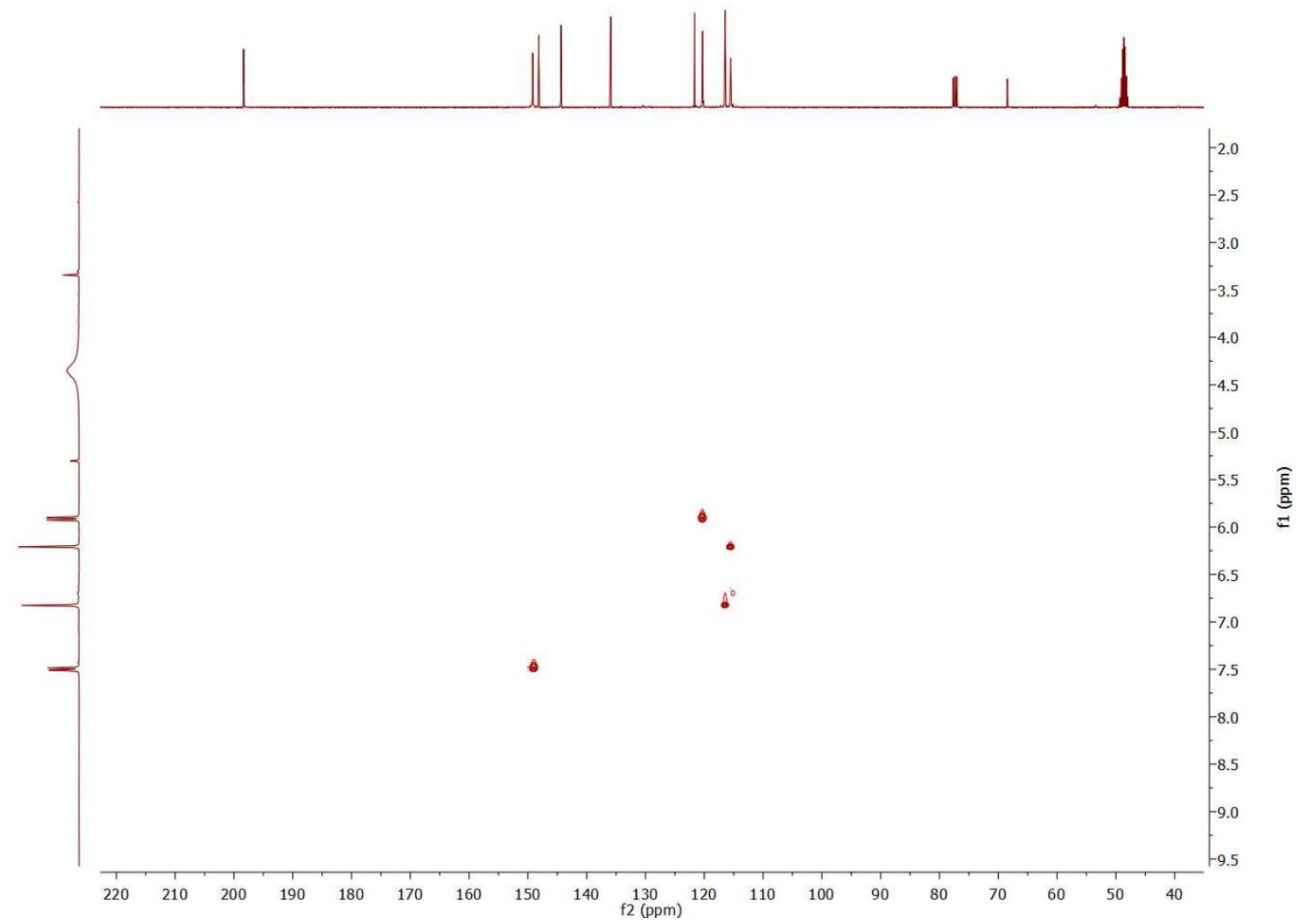


COSY spectrum of Spiroaxillarone A (1)

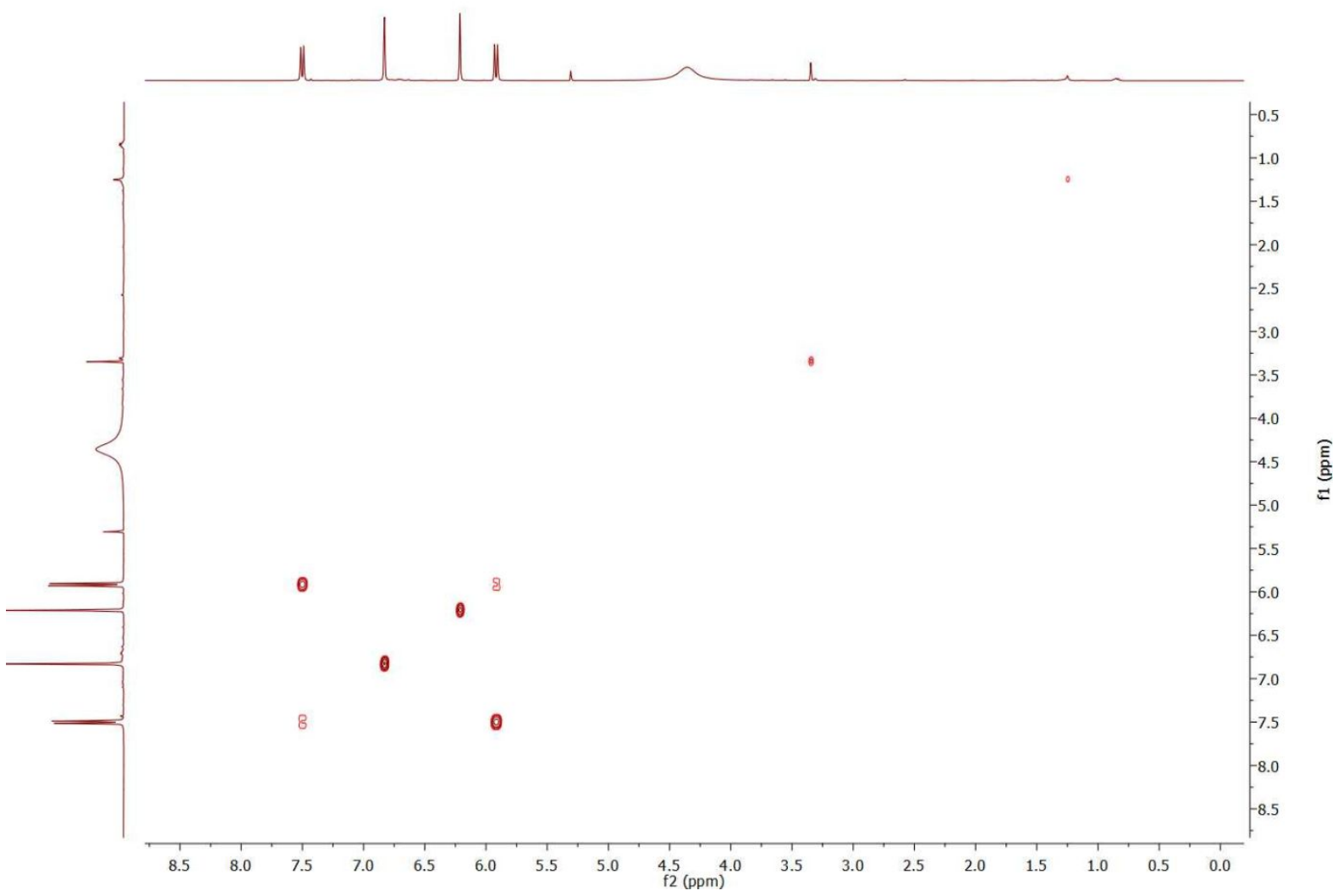

HMBC spectrum of Spiroaxillarone A (1)

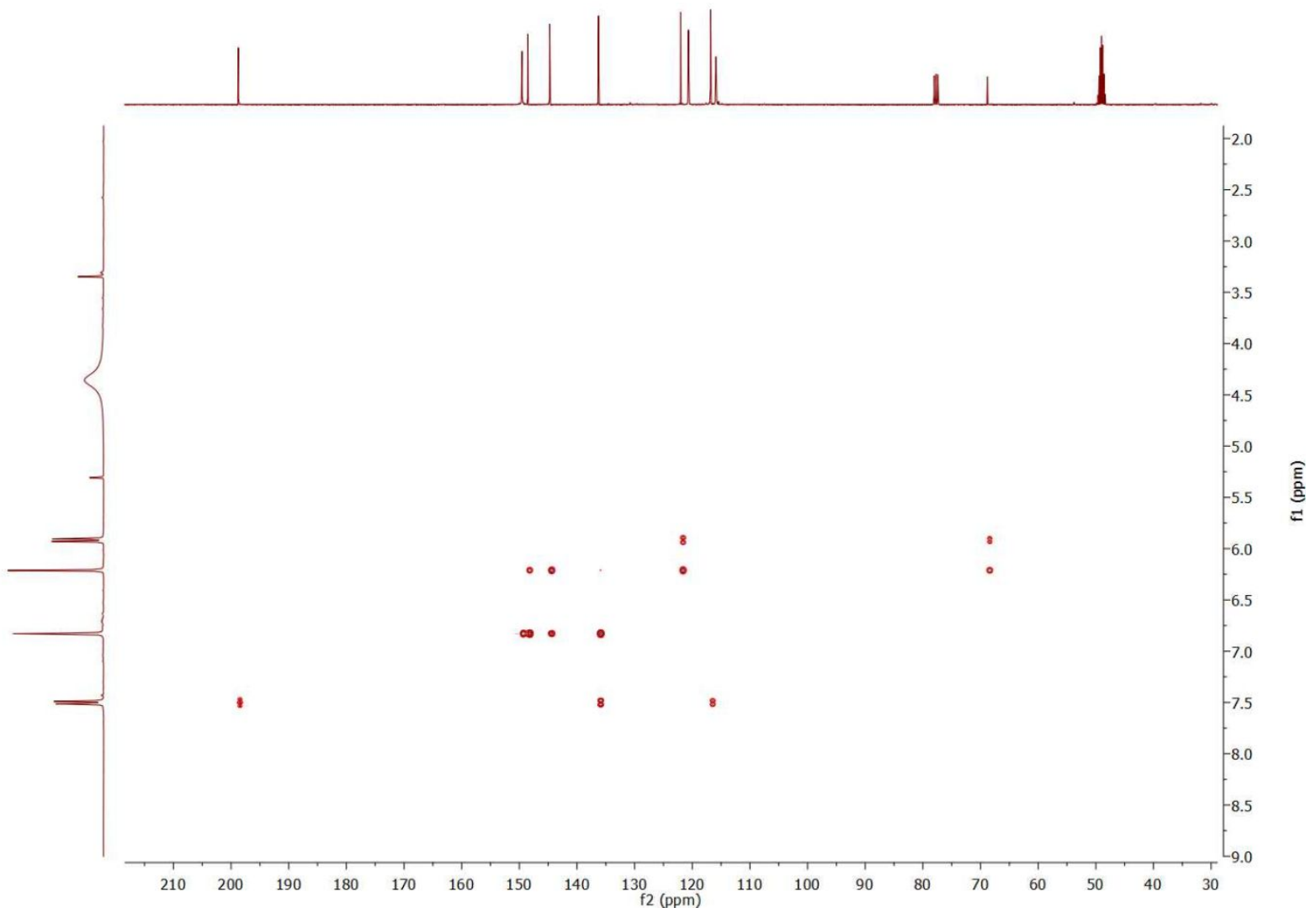


2.2 HR-ESIMS spectrum of Spiroaxillarone A (1)

\section{Mass Spectrum List Report}

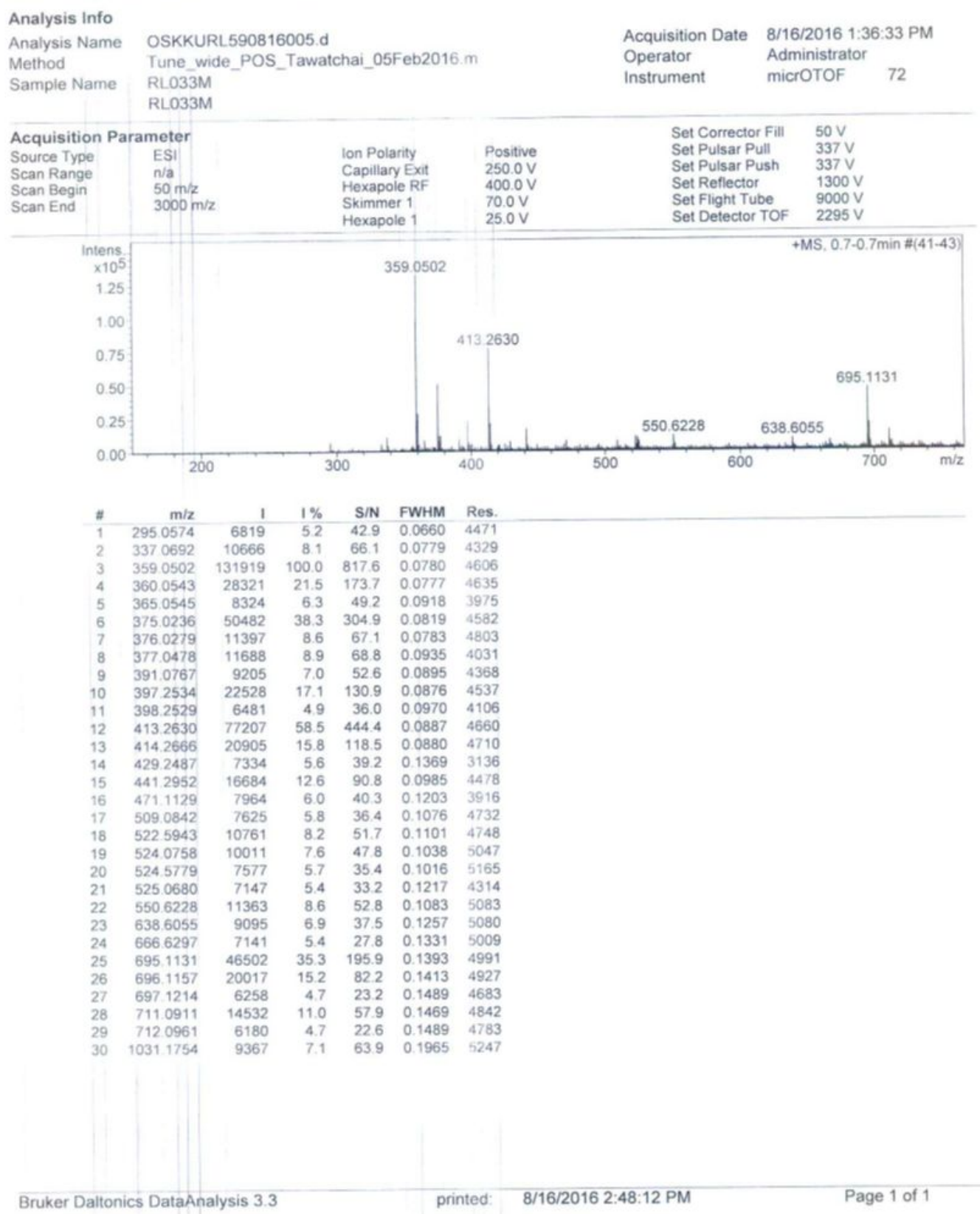


2.3 IR spectrum of Spiroaxillarone A (1)

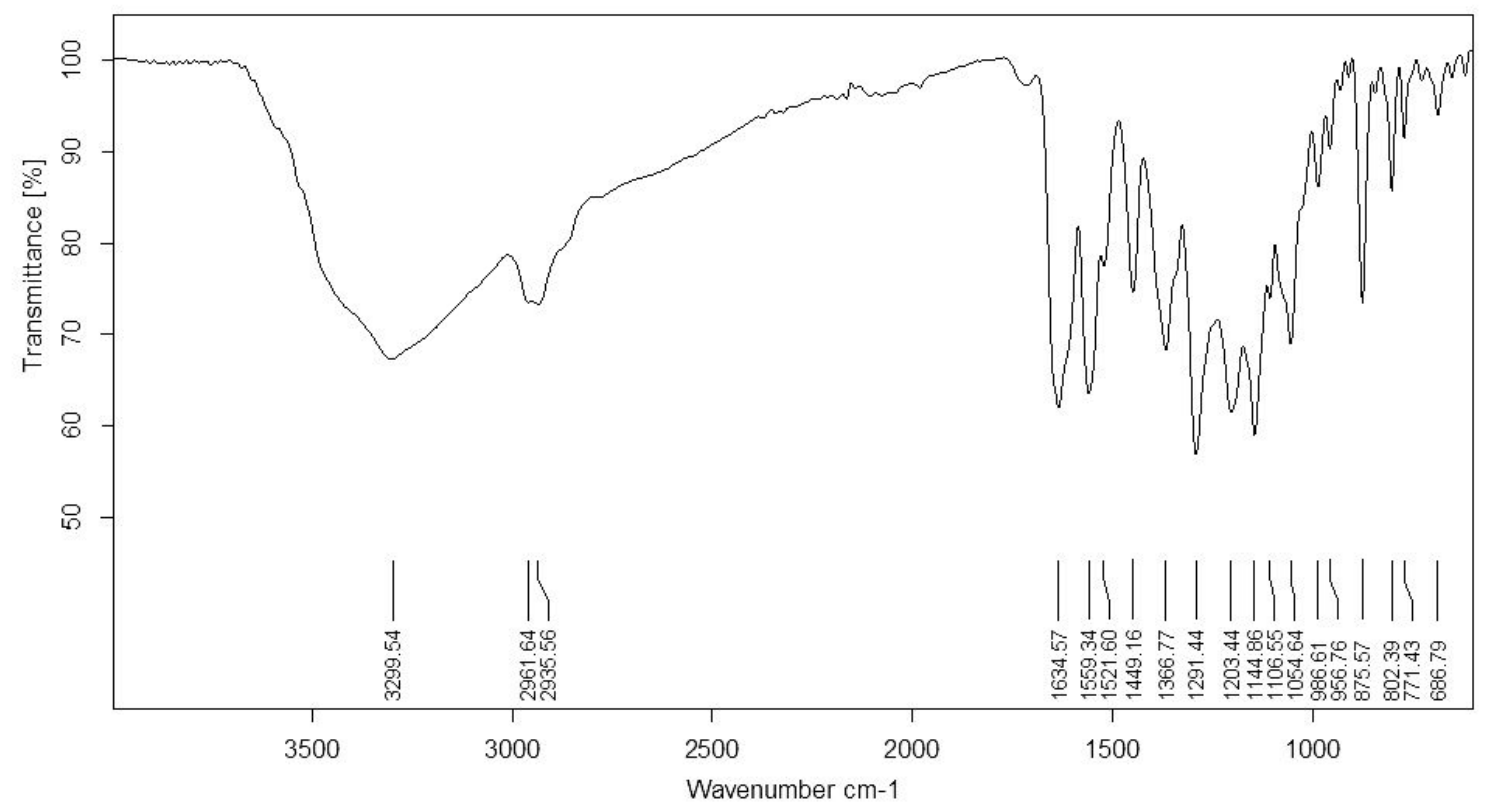

2.4 UV spectrum of Spiroaxillarone A (1) in methanol

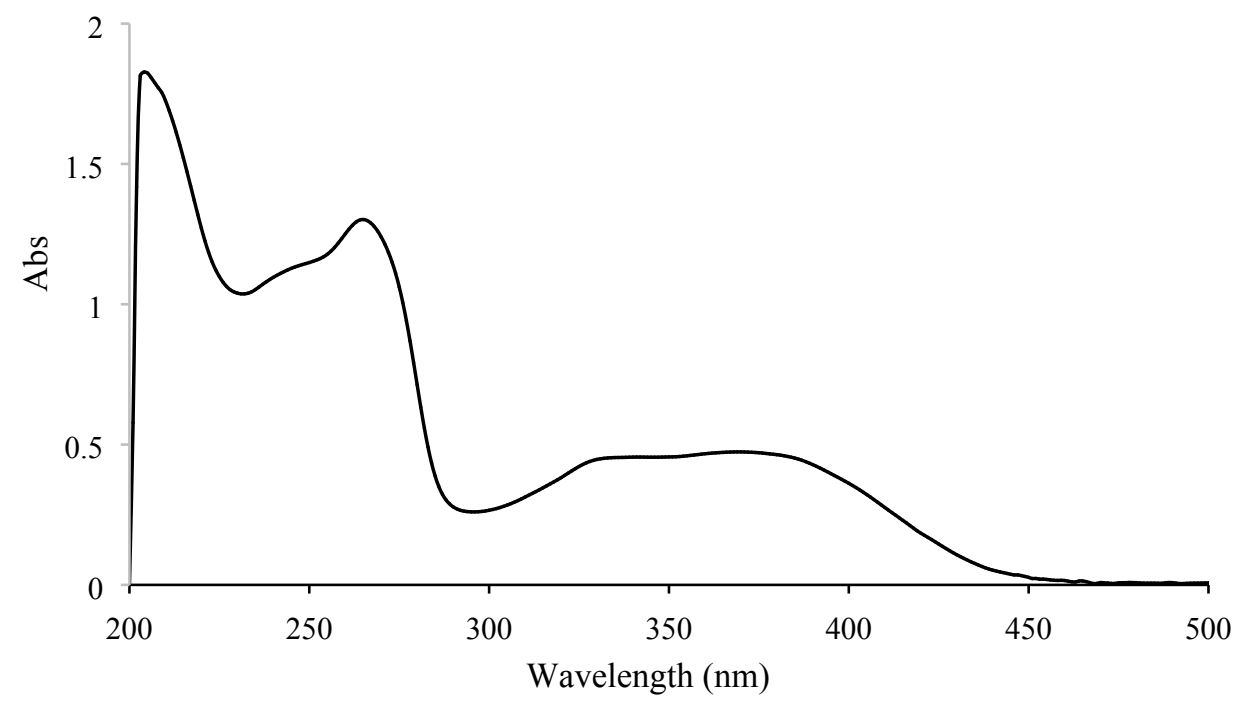


$2.5{ }^{1} \mathrm{H}$ NMR spectrum $(400 \mathrm{MHz})$ of $1 \mathrm{a}$

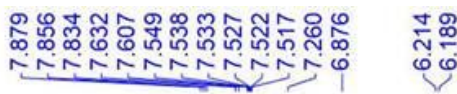<smiles>O=C(Oc1cc2c(cc1OC(=O)c1ccc(Br)cc1)C1(C(=O)C=C2)C(=O)C=Cc2cc(OC(=O)c3ccc(Br)cc3)c(OC(=O)c3ccc(Br)cc3)cc21)c1ccc(Br)cc1</smiles>

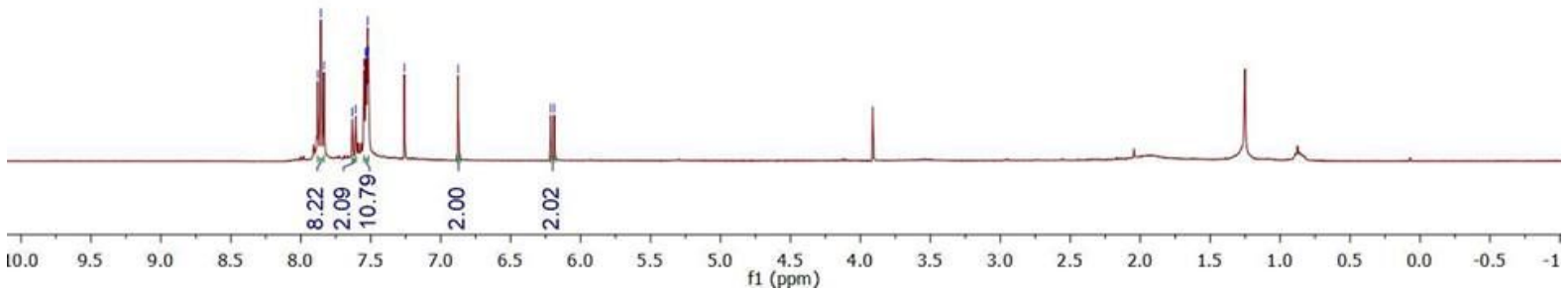

$2.6{ }^{13} \mathrm{C}$ NMR spectrum (150 MHz) of 1a
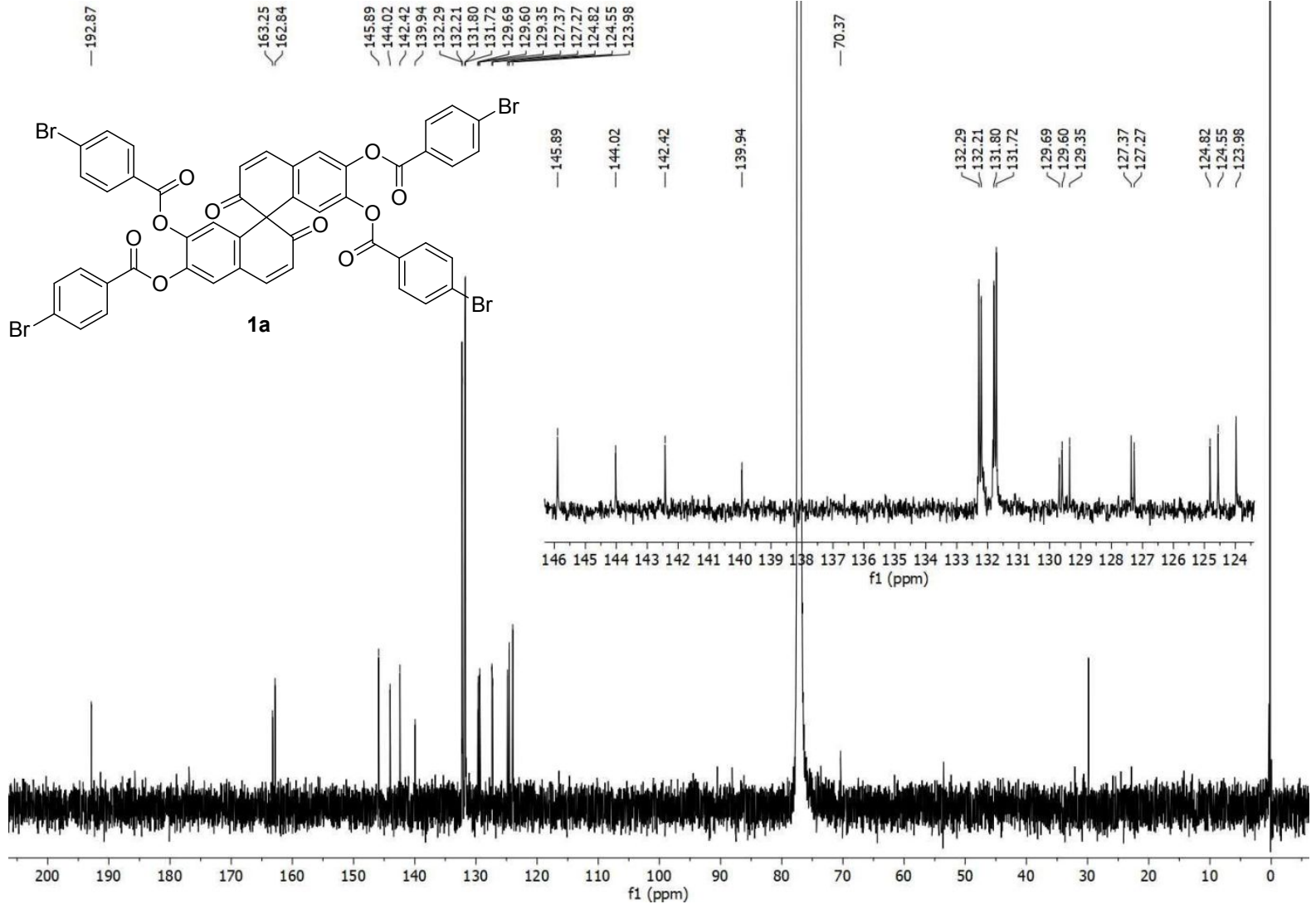


\subsection{HR-ESIMS spectrum of 1a}

\section{Mass Spectrum List Report}

\section{Analysis Info}

Analysis Name OSKKURL8092019001.d

Method Tune_wide_POS_Natee20130403.m

Sample Name

$1 \mathrm{~A}$

$1 \mathrm{~A}$

Acquisition Date 9/18/2019 2:03:43 PM

Operator Administrator

Instrument micrOTOF 72

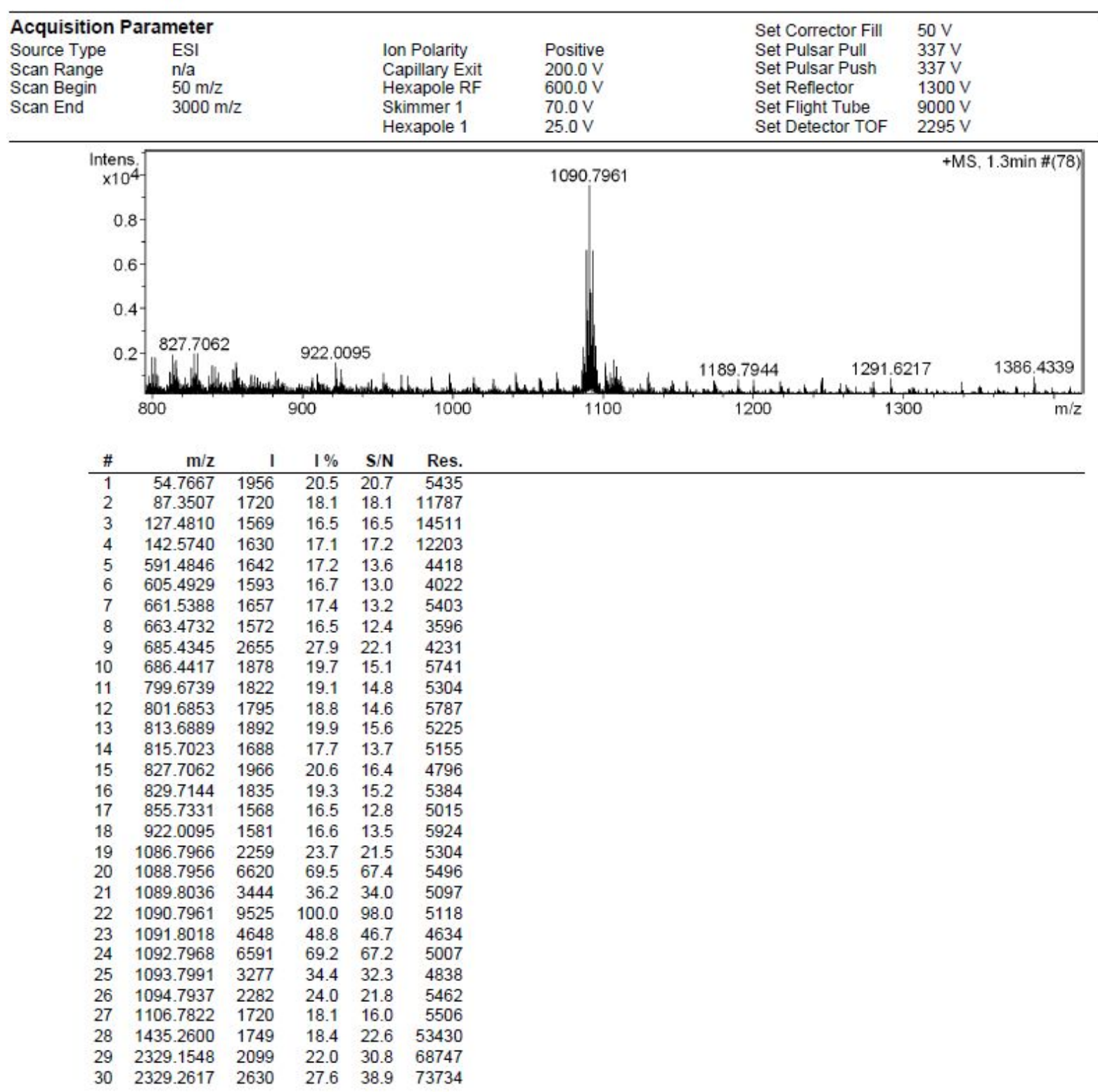

